\title{
تعليم اللغة العربية من خلال كتاب دروس اللغة العربية لإمام زركثي و إمام شباني بالمدرسة الثانوية العامة النور تيبينج سولوه اوكان كوميريع ايلير
}

\author{
${ }^{1}$ Maimunah, ${ }^{2}$ Awalia Irfandi \\ Email: maimunah_uin@radenfatah.ac.id \\ 1,2 جامعة رادين فتاح الإسلامية الحكومية فالمبانج \\ ملخص: تعليم اللغة العربية من خلال كتاب دروس اللغة العربية لإمام زركشي و إمام شباني بالمدرسة الثانوية العامة النور تيبينج سولوه اوكان كوميريع \\ ايلير. أما عملية تعليم اللغة العربية الجيدة هي تعليم الذي يهتم ببعض مكونات التعليم مثل: طريقة التدريس، وسائل التعليمية، مادة الدرس، التقويم \\ في إيصال المادة الذي يطابق بشكل التعليم فهو تعليم اللغة العربية.و أن مزايا و نقصان باستخدام كتاب المدرسي يمكن رؤية من مزايا و نقصان في

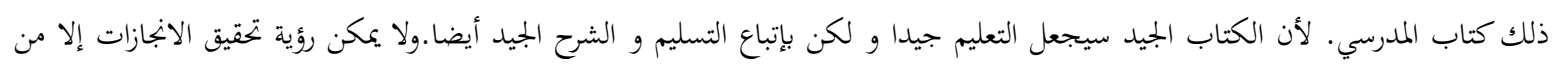 \\ نتائج تقويم الطلبة النهائية، و لكن يجب أن ينظر من إستجابة الطلبة حين أثناء التعليم مند بداية حتى فاية، و إجراء التقييم فى كل فرصة. \\ الكلمات المفتاح: طريقة ، وسائل ، مادة ، التقويم، كتب المدرسية
}

\begin{abstract}
Abstrak: Pembelajaran bahasa Arab dengan menggunakan buku Durus Al-Lughah Al-Arabiyah Li Imam Zarkasyi Wa Imam Subbani di SMP an-Nur Tebing Suluh Ogan Komering Ilir. Pelaksanaan pembelajaran bahasa arab yang bagus adalah pembelajaran yang memperhatikan beberapa komponen-komponen dalam pembelajaran seperti: metode, media, materi, dan evaluasi yang sesuai dengan bentuk pembelajarannyan nitu sendiri yakni pembelajaran bahasa Arab. Kelebihan dan kekurangan dengan menggunakan suatu buku ajar bisa dilihat dari kelebihan dan kekurangan buku itu sendiri karena buku yang baik akan menjadikan pembelajaran baik pula tetapi dengan diikutinya penyampaian dan penjelasan dari guru yang baik pula. Pencapaian hasil belajar tidak bisa dilihat hanya dari nilai siswa di akhir tetapi haru melihat respon siswa selama mengikuti pelajaran dari pertama hingga terakhir, dan kegiatan evaluasi di setiap tahapan.
\end{abstract}

Kata kunci: Metode, Media, Materi, Evaluasi, Buku Ajar

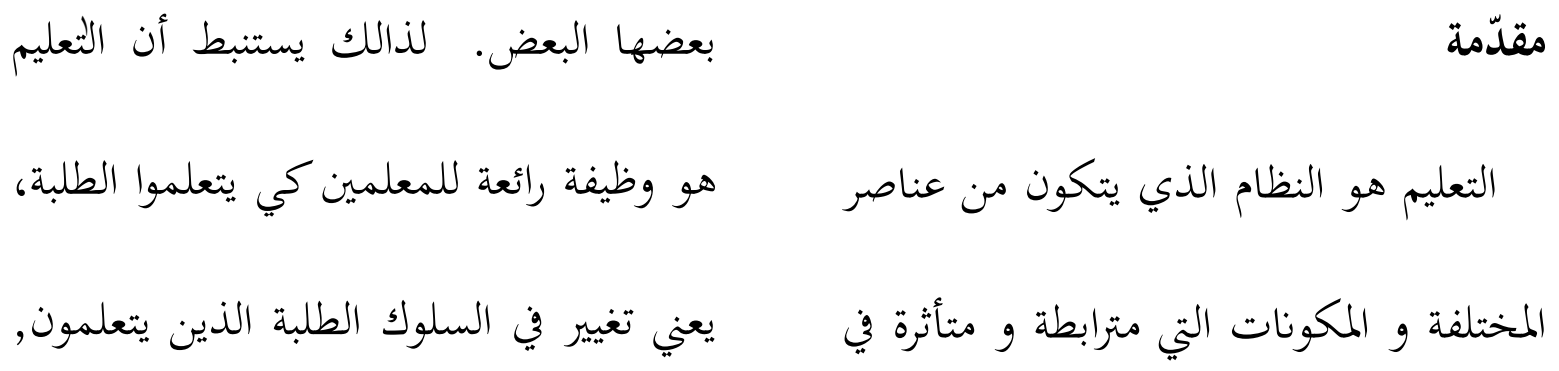

${ }^{1}$ Munir. 2011. Perencanaan Sistem Pembelajaran Bahasa Arab Teori Dan Praktek. Yogyakarta: Idea Press, hal. 5 
ينبغي على المعلم أن ينظر إلى طريقة

التعليم حتى لا تزول محبة التعلم في نفس

الطلبة، و في عملية التعليم أيضا تنبغي أن

تخضر الجو الجذاب و السرور لطلبة في كل

مادة الدرس المختلفة، ليتشط و ينمي دوافع

التعلم. أما نوع التعلم ينظر من الأهداف و

النتائج التي تم الحصول عليها من التعلم يقول

الخبراء عموما ينقسم التعلم إلى ثمانية أنواع،

هي: دراسة النظرية، دراسة المهارة، دراسة

الإجتماعية، دراسة حل المشكلة، دراسة

العقلية، دراسة العادة، دراسة التقديرية،

دراسة الثقافة.

تعليم اللغة العربية يختلف بتعليم اللغة الأم.

قد إختلفت مبادئ الأساسية في تعليم اللغة

${ }^{2}$ Muhibbin Syah, Psikologi Pendidikan Dengan Pendekatan Baru.Bandung:PT. Remaja Rosdakarya.2010 hal. 120

تعليم اللغة العربية من خلال كتاب دروس اللغة العربية لإمام زركشي و إمام شباني بالمدرسة الثانوية العامة النور تيبينج سولوه اوكان كوميريع ايلير
حيث كان التغيير مع وجود إكتساب المهارات الجديدة المعمولة بها في زمن طويل نسبيا و وجود الجههد. قالا محمود ينوس و محمود قسم بكري في كتابهما أنّ التعليم هو

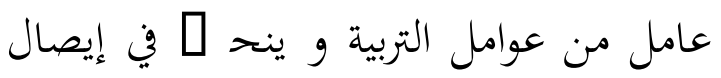
معلومات إلى ذهن و صكّّ حوافظ الناس

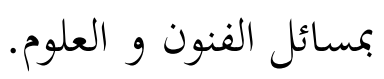
عملية التعليم تمكن أن بحلب مشاعر عدم المريح لطلبة أحيانا يسبب من تطبيق طريقة معينة لا تتوافق مع حالة الطلبة. لذلك ينبغي على المعلم أن ينظر إلى طريقة التعليم حتى لا تزول محبة التعلم في نفس الطلبة، و في عملية التعليم أيضا تنبغي أن تخضر الجو الجذاب و السرور لطلبة في كل مادة الدرس المختلفة، ليتنشط و ينمي دوافع التعلم. 
الكتب التي سمّها بالكتاب الأصفر، وذلك تعليم اللغة العربية يجد في معاهد السلافية

و رأت الباحثة أن عملية تعليم اللغة العربية في المدرسة الثانوية النور لها تمييز أخرى من غيرها بين المدارس الموجودة في تلك المنطقة. هذه المدرسة التي تقف فوق المؤسسة بمعهد السلافية النور تطبّق تعليم اللغة العربية في المدرسة بإستخدام كتاب الدروس اللغة العربية, هذا الكتاب عادة يواجه أو يستخدم في المعاهد الحلديثة. لو كان هذه المدرسة لها خلفية مؤسسة بمعهد السلافية ولكن هذه المدرسة لاتريد إلا تتصارع بكتب الأصفر أو طريقة تعليم التقليدي كنظم. وهذا واضح من الرغبة في عملية تعليم اللغة العربية كانت
العربية من حيث طريقة، أو مادة، أو عملية التعليم. لأن اللغة ليست القدرة الفطرية لكنها الإنجاز من الأنشطة بالجد، و تحتاج إلى عملية التعليم التفضي و تحتاج إلى المرافق و البيئة الداعمة. تعليم اللغة العربية بمعنى تعليم من تلك ناحيات اللغة، و من كل ناحية اللغة لها خصائ [] التي تختلف عن

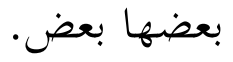
تعليم اللغة العربية عموما لها أهداف كأدة المهارة أو الخبرة في العلم او الثقافة. وإن التعليم السليم في المادة السليمة. أما الأن، إبتحاه تعليم اللغة العربية ليس لفهم القرأن و الحميث فقط، أو فهم الن 1 الدين أو قراءة الن U العربية، كما فعل الناس في الماضى، يعنى يتعلمون اللغة العربية كي يفهمو أنواع 
عالية جدا وأفا إستمتعت حقا عملية تعليم الكتب أخرجه قسم التعليم

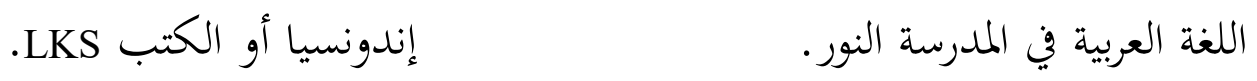
في هذه الحالة فيما تتعلق بعملية تعليم الإطار النظري اللغة العربية, وخاصة في المدرسة الثانوية النور تعليم اللغة العربية

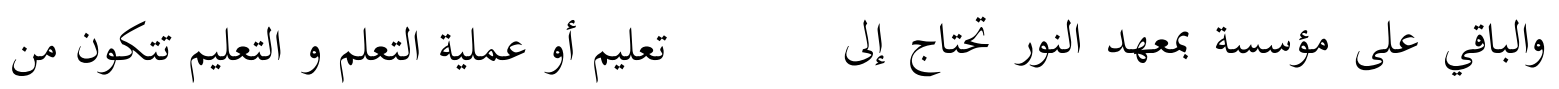
إهتمام من أجل أن تصبح مثالا لغيرها من عملية التعلم التي تقوم بها الطلبة و التعليم أو المدارس الأخرى كي تلك المدارس تمكن أن التدريس الذي يقوم به المعلم ليجعل الطلبة تكون أكثر التقدم وتخرج الأجيال المتميزة. تعلما. تعريف التعليم في كتاب التربية و تعليم اللغة العربية من خلال كتاب دروس التعليم هو مساعدة الطلبة لإنماء قواهم اللغة العبية لإمام زركشي و إمام شباني العقلية و الخلقية و تنظيمها حتى يتحلوا بالمدرسة الثانوية النور تيبينج سولوه اوكان بلأخلاق الكريمة و يستعدوا لمستقبلهم. و كوميريع ايلير. و دوافع التي دفعت الباحثة هو ليس مجرد إيصال المعلومات إلى أذهان إختارت هذا العنوان لأن تعليم اللغة العربية الطلبة و صب حوافظ النشء بمسائل الفنون التي وجدنا كثيرا في المدارس العامة تستخدم الكتب كالكتاب إيطبوع 
العربية هي عملية التربوية تمدف إلى الدفع و الإرشاد و التطوير في بناء قدرة اللغة العربية الصحيحة إيجابية أو سلبية. لذلك يتم إعداد اللغة العربية في المدرسة لتحقيق كفاءة اللغوية الأساسية أتي تشمل إلى أربع مهارات اللغوية تتم تدريسها بشكل متكامل، يعني الاستماع والكلام والقراءة والكتابة.

لتسهيل الطلبة إلى عملية تعليم أهم أن تكون هناك مدرس اللغة العربية المهني الذي يتقن اللغة الغُبية حقا، سواء عن قواعد اللغة العببية والمهارات في اللغة العربية. لأن التعليم السرور يعني التعليم الذي يطابق بالجوي المحدث في نفس الطلبة. سيكون في التعليم هناك مكونات تجب أن توجد. على نحو
و العلوم. و يقال أيضا إن عمليةّّ التعليم هي جزء من عملية التربوية الكاملة، ترمي أساسا إلى تنمية عقل الفرد و تمكينه من اكتساب المعرفة و المهارة اللازمة لحياته, و درايته بعلم ما أو فن ما, أو حرفة ما, و نحو ذلك. و عند الغلاييني أن اللغة العربية هي الكلمات التي يعبّر بها العرب عن أغراضهم. وقد وصلت إلينا من طريق النقل. وحفظها لنا القرآن الكريم والأحاديث الشريفة، وما رواه الثقات من منثور العرب ومنظومهم. و من تعريف التعليم و اللغة العربية على أساس المعاني المختلفة، يمكن استنتاج أن تعليم اللغة

r سوترسنو أحمد و حسن المعافي، رفعت و بوديمان، أغوس و الحافظ زيد،

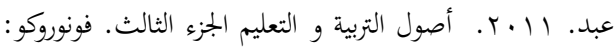

بمعهد دار السلام كونتر للتربية الإسلامية الحديثة. ص. •

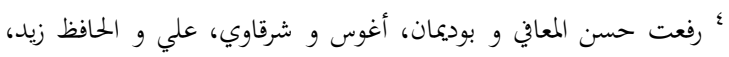

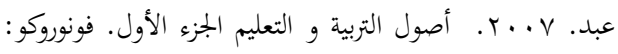

بكعهد دار السلام كونتر للتربية الإسلامية الحديثة. ص. V.

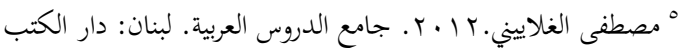
العلمية. ص. 
ذلك. وجود طريقة تحتل مكّانة مركزية و

مهمة في تسليم مادة الدرس، واختيار الطريقة

غير لائقة سوف يؤدي إلى فشل في التعليم .

بالتالي أهمية من استخدام و اختيار الطريقة

المستخدمة بالمعلم عند تدريس اللغة العربية،

لأن الطريقة تؤثر على عملية التعليم والنتيجة

من تعليم اللغة العربية الذي يشمل أربع

$$
\text { المهارات اللغوية. }
$$

ب) وسائل التعليمية

وسائل التدريس أو وسائل الإيضاح هي

كل ما يستعين بها المدرس على إيصال المادة

العلمية و سائر المعارف و القيم إلى أذهان

الطلبة و توضيحها. وسائل الإضاح نوعان :

${ }^{6}$ Ulin Nuha. 2016. Ragam Metodologi Dan Media Pembelajaran Bahasa Arab Super Efektif, Kreatif, Dan Inofatif. Yogyakarta: Difa Press. Hal. 153
التالي: طريقة التدريس، ووسائل التدريس، و

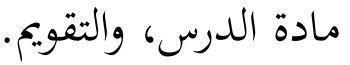

$$
\text { أ) طريقة التدريس }
$$

طريقة التدريس هي الطريقة المستخدمة

لتنفيذ الخطة التي تمت إعدادها في شكل

أنشطة الظاهرة والواقعي لتحقيق أهداف

التعليم. أكثر ملائمة الطريقة التي تستخدم في

عملية التدريس فأكثر فعالية ومؤثرة عملية

التعليم أيضا التي تقوم بها المعلمين والمتعلمين.

في هاية التعليم سوف تدعم وتقدم نجاحة

التعليم التي يقوم بها المعلم.

إما اختيار وتحديد طريقة التعليم الذي

سيستخدم المعلم في التعلم والتعليم بالطبع

يرتبط ارتباطا وثيقا بقيمة الاستراتيجيات

والطريقة و فعالية استخدام الطريقة، و غير 
استخدام وسائل التدريس لتوفير المعرفة

أكثر دقة و سهولة فهمها لمتعلمين، وخاصة

لمتعلمين اللغة العربية. إما الطريقة المستخدمة

لتعليم اللغة العربية هي المطابقة بأربع المهارات

في اللغة العربية، على سبيل المثال وسائل

الإعلام السمعية لمهارة الإستماع، ووسائل

الصورة لمهارة الكلام، ووسائل عرض التقديم

لمهارة القراءة، ووسائل لعبة الطائش الكلمة

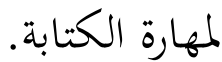

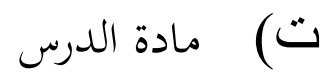

مادة الدرس هي المكونات التي تجب أن

تكون موجودة في عملية التعليم سواء

المؤسسات الرسمية وغير الرسمية .لأن نجاح أو

غير النجاح التعليم يعتمد على طول و صلبة

تلك مواد الدرس تتمكن بالطلبة.
الوسائل الحسية و الوسائل اللغوية. (سوترسنو

أحمد، 1)

الوسائل الحسية هي ما يؤثر فن القوى

العقلية بواسطة الحواس, بغرض نفس الشيء

أو نموذجه أو صورته و نحو ذلك. وتشتمل

على وسائل سمعية, ووسائل بصرية, ووسائل

سمعية بصرية, ووسائل لمسية, ووسائل شمية.

الوسائل اللغوية هي ما يؤثر فن القوى العقلية

بواسطة الألفاظ. و تشتمل الوسائل اللغوية

على: الأمثلة, و و القصة, و المحادثة, و

والوصف, و التمثيل, ووضح الكلمة في جملة

مفيدة عندما تستخدم لتوضيح المعاني و

V

الحقائق.

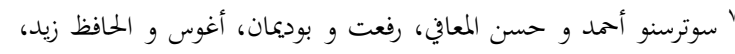

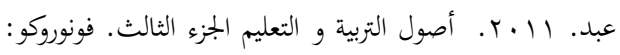

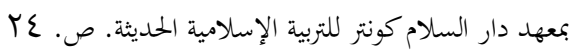


و هناك بعض مبادئ عامة بحب مراعتها تشمل عن: القاموس، وكتب التدريب، وقراءة فن إختيار مادة الدرس و ترتيبها منها : الكتب، وكتاب التوجيهية للمعلم.

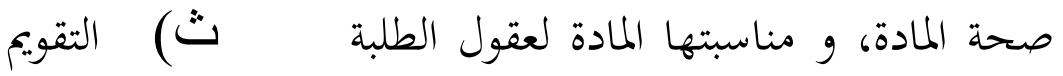
من حيث مستواها، أن تكون المادة المختارة التقويم هو تبيان قيمة الشيء أو قيمة مرتبطة بحياة الطلبة و بالبيئة التى تعيش فيها، الشخ ل الثقافية أو العلمية أو نهو ذلك. أن تكون المادة مناسبة لوقت الحصة، أن غرضه العام هو إعطاء الناجحين شهادة تدل ترتّب المادة ترتيبا منطقيا، أن تقسم مادة على انتهائهم من مرحلة تعليم الثانوي. المقرر إلى وحدات توزع على شهور السنة، ويكون التقيم شفويا أو كتابيا أو عمليا. ربط مادة الدرس الجديدة بمادة الدرس ق قال عبد الرحمن بن إبراهيم الفوزان في القديمة, أو ربط موضوع الدرس بغيره من كتابه، عندما توجه أسئلة اللغة العربية إلى

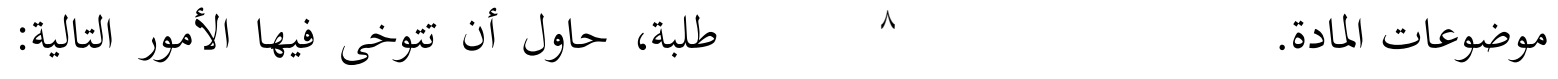
بالإضافة إلى مواد الرئيسية في كتاب

${ }^{9}$ Syamsuddin Asyrofi Dan Toni Pransiska. 2016. Penulisan Buku Teks Bahasa Arab Konsep, Prinsip Problematika Dan Proyeksi. Yogyakarta: Ombak. Hal. 46

المدرسي يحتاج على مواد الداعمة، و مخطط أن مواد الداعمة لكتب المدرسية العربية

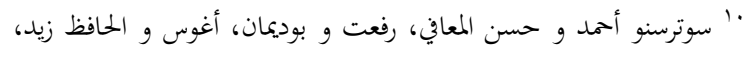

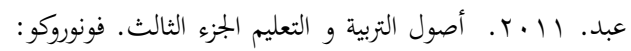

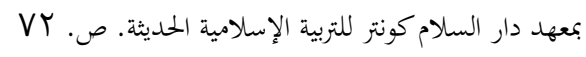

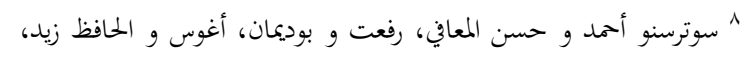

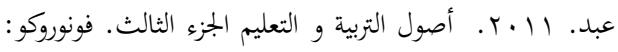

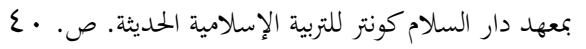


وهكذا، فإن المعلم له وقت الكثير لتوجيه

الطلبة في التعليم. لإعداد مواد تعليمية

الجيدة، يجب أن نعتبر مبادئ فن تقديم المواد

اللغة العربية. أما كتاب المدرسي الذي لا

يعتبر مبادئ في تقديم المواد اللغة العربية أن

تكون مشكلة واضحة في تحقيق الأهداف.

تلك المبادئ هي اختيار (اختيار المواد)،

وتدرج (مستوية)، و تقديم (العرض) وتكرار

(دورة التدريبية).

فإن أفضل كتاب المدرسي، فأكمل الدروس

الذى كفئه. كتاب مدرسي اللغة العربية الذي

له جودة فيساعد طبقة من تعليم اللغة العربية

واضح. لأن أفضل الكتاب المدرسي، وأكثر
(عبد الرحمن بن إبراهيم الفوزان: آبـ ا هـ،

$(1 \leq$

1) أن تكون السؤال واضحة الصياغة مناسبًا

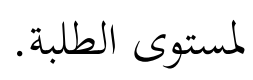

2) لا تحتوي السؤال على معلومات جديدة

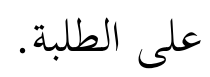

3) أن تكون السؤال موجزة وقصيرة.

4) أن تكون السؤال محددة دقيقة.

5) أن تعتمد الإجابة عنها على التفكير

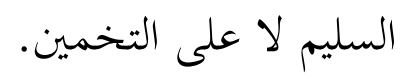

$$
\text { ج) جودة الكتب المدرسية }
$$

يمكن اعتبار الكتاب المدرسي كمواد

التعليمية التي سيبلغ المعلم إلى الطلبة. وجود

الكتاب المدرسي يمكن أن تجعل الفعالية من

استخدام الوقت في تقديم محتوى التعليم.

${ }^{1}$ Acep Hermawan. 2014. ${ }^{1}$ Metodologi

Pembelajaran Bahasa Arab. Bandung:

Remaja Rosdakarya, hal. 107

تعليم اللغة العربية من خلال كتاب دروس اللغة العربية لإمام زركشي و إمام شباني بالمدرسة الثانوية العامة النور تيبينج سولوه اوكان كوميريع ايلير 
أما طريقة آلجمع البيانات إستخدمث الباحثة

أنواع الطريقة لجمع البيانات في هذ البحث،

وهي: الملاحظة، المقابلة، و التوثيقي.

الملاحظة لمعرفة عملية تعليم اللغة العربية في

المدرسة النور من خلال كتاب دروس اللغة

العربية لإمام زركشي و إمام شباني. والمقابلة

لمعرفة مزايا و نقصان من تعليم اللغة العربية

من خلال كتاب دروس اللغة العربية لإمام

زركشي و إمام شباني. و التوثيقي تحقيق

إنجازات التعليم من خلال كتاب دروس اللغة

العربية لإمام زركشي و إمام شباني.

نتائج البحث

عملية تعليم اللغة العربية بالمدرسة الثانوية

العامة النور من خلال كتاب دروس اللغة

العربية مام زركثي و امام شبالي
كمالا تعليم الموضوعات التي يدعمها. ـإما

معايير كتاب المدرسي اللغة العربية الجيد

الذي يتعين الوفاء به هو كما يلي: القراءات،

قواعد اللغة العربية، التمرينات، مراحل عرض

المواد التعليمية، وجود القاموس القصير.

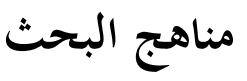

أما المدخل في هذا البحث يعنى البحث

الكيفي مع تصميم دراسة الحالة من شأنه أن

إستكشاف في التفصيل وعمق البيانات

الميدانية. محور هذه الدراسة هو تعليم اللغة

العربية من خلال كتاب دروس اللغة العربية.

نوع المنهج في هذه الدراسة هو حل المشكلة

(الوصفي) التي موجودة على الأسس

1 Tarigan, Henry Guntur. 2009. Telaah Buku Teks Bahasa Indonesia. Bandung: Angkasa, hal. 20 
أن في عملية التعليم لا يركز المعلم دائما ولكن باستخدام وسائل التعليمية، لكي تبقى على الدرس باستخدام طريقة المحاضرة دائما، الكلمة في أذهان الطلبة، لأن عادة المتعلم لأن الطلبة سوف يواجهون التشبع في تعليم أكثر اهتماما وسهلة لتذكير أشياء مثيرة اللغة العربية. ولكن المعلم يعلم اللغة العربية للاهتمام. الطريقة هي أن بعد اتباع الطلبة بتخليلها طريقة اللعبة بحيث أن الطلبة لا الكلمات التي تم نطقها المعلم، المعلم يعطي يشعروا بالملل في عملية التعليم ومن المتوقع أن وسائل الإعلام كالصورة أو جلب الكائن تكون أكثر نشاطا مرة أخرى. أما اللعبة مباشرة أمام الطلبة. إذا كانت الطلبة يعرفون المستخدمة هي لعبة التي لا تزال في بجال معنى الكلمة فيكتبها المعلم على السبورة التعليم، والتي لا تخرج من مناقشة المواد في ويطلب من جميع الطلبة قراءتا، بحيث يعلم

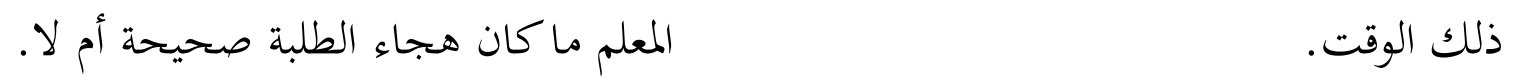
أعطى المعلم المفردات بطريق التلفظ مزايا و نقصان من تعليم اللغة العربية من المفردات التكرار ثم الإعادة بالطلبة. ويككن خلال كتاب دروس اللغة العبية مام استخدام هذه الطريقة لتدريب سمعهم في زركشي و امام شباني استماع الكلمة العربية. أما بالنسبة لشرح لمعرفة مزايا ونقصان من تعليم اللغة العربية المعنى من المفردات لا يقول المعلم على الفور باستخدام كتاب دروس اللغة العربية لإمام 
يستكمل بالقاموس أو معجم المصطلحة. أما تعليم اللغة العربية الجيد هو تعليم الذي يستخدم كتابا جيدا أيضا(مستمل بمبادئ في تقديم المواد) مع اتباع طريقة وإلقاء من معلم اللغة العببية الجيدة كذلك. لأن بدون التسليم الجيد من المعلم، المادة الجيدة كما أي كان لا تزال الصعبة لفهم وهضمها من قبل المتعلمين. ومن التحليل الذي حصلت عليه الباحثة من المقابلة و الملاحظة قام المعلم بتطبيق الطريقة لتبسيط عملية تعليم اللغة العربية و لكي يسهل الطلبة لفهم المواد التي تدرس، خصوصا لمعرفة المعنى من كل المفردات الجديدة. يعني بالطريقة يشرح المعلم المفردات الجديدة والصعبة واحدا فواحدا باستخدام
زركشي وإمام شباني فأولا تستعمل الباحثة نظرية في إعداد الكتاب المدرسي لمعرفة مزايا ونقصان من ذلك الكتاب المدرسي. من ناحية ملائمة الختويات، بشكل عام أن الكتاب المدرسي هو موافقا بمؤشرات تقييم ملائمة محتوى الكتاب، لأنه وفقا بنظرية في إعداد الكتاب المدرسي الجيد(الاختيار، التدرج، العرض، التكرار). المواد في الكتاب المدرسي هي دقيقة وعميقة لأها تأتي فيه المفاهيم، و الصورة، والتوضيحية الظاهرة و القهرية. من الناحية العرضية أن العرض من التعليم واكمال العرض بشكل العام هو موافقا بمؤشرات تقييم ملائمة العرض. فقط من حيث اكتمال العرض، في جزء الاخر لم 
وسائل الإعلام أو الدعائم المقابلة بالمفردات (الإستماع، الكلام، القراءة، و الكتابة). من خلال لا يبلغ المعلم معنى من كل واستنادا في الكتاب دروس اللغة العربية لإمام المفردات مباشرة، بحيث ذاكرة المتعلم عن زركشي و إمام شباني وهذا الكتاب يشمل المفردات يذكر منذ فترة طويلة. و جمع هذا أسئلة التقويم في كل موضوع مادة الدرس، الكتاب من قبل الإمام زركشي والإمام شباني وهو يقع في فاية المادة. ويي المدرسة الثانوية خصوصا لمتعلمين المبتدئين اللغة العربية في العامة النور نفذ هذا التقويم تدييجيا، وهذا هو إندونيسيا. تم تكييف موضوع المواد لظروف عندما عملية التعليم، والتقويم اليومي، وتقويم المتعلم، لذلك فمن الممكن لاستخدامه في المحتوى الدراسي.

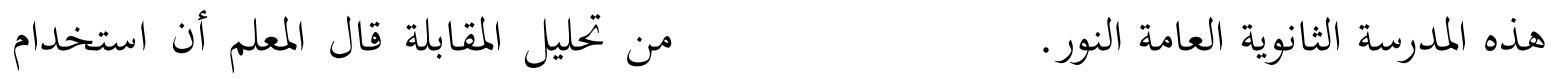
تحقيق الإنجازات التعليم من خلال كتاب هذا الكتاب هو جيد وفعالية. لأن الطلبة دروس اللغة العربية مام زركثي و امام تحسن في التعليم مقارنة بمعاينة في السنة الأولى عندما لا يزال يستخدم LKS. شبالي يجب أن يكون التقويم وفقا لخصائ ] [ باستخدام هذا الكتاب قال المعلم أيضا أن تعليم اللغة العربية، أي الأسئلة التي تتم القيمة التي يكصل الطلبة على كل التقويم فوق

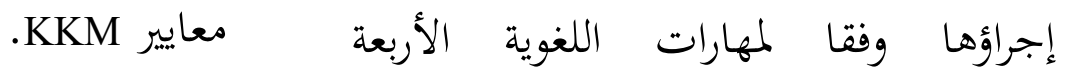


ومن الملاحظة التي ترى الباحثة، ما قال فيمكن القول أن درس اللغة العربية

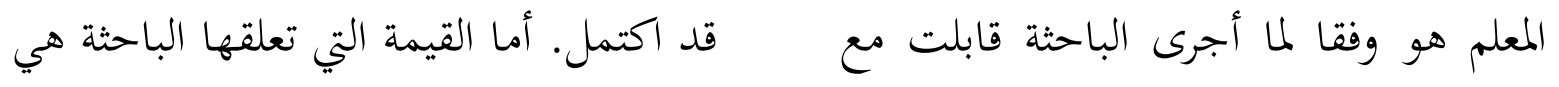
المعلم. من حيث فهم الطلبة، ومستقبلهم قيمة الطلبة الصف التاسع أ. وضح التحليل أن قيمة الطالبات تقع فوق يثبت أغم فهم حقا المواد الموصوفة. حتى لو معايير الاكتمال حد الأدنى (KKM) المعاينة كانوا لم يفهموا سوف يكونون الشجاعة هي ·V. تردد الأعلى من قيمة الطالبات هي ليسئلوا الم المعلم. كما في نشاط المراقبة ه1 المعادلة ع الطالبات، و تردد الثاني من والسؤال، يبدو الطلبة خطيرة متابعة التعليم. قيمة الطالبات هي rم المعادلة ا الطالبة، و يشجع الطلبة رفع أيديهم لطرح المعلم حول تردد الثالث من قيمة الطالبات هي 1، 16 المعادلة V الطالبات ، و أما الباقي عدد قيمة و كل ذلك ثبت من خلال توثيق قيمة الطالبات ما زال فوق معايير الاكتمال حد الطلبة في امتحان المحتوى الدراسي. وتبين أن

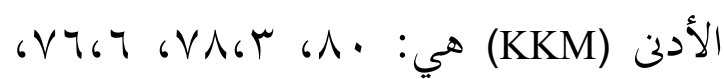
قيمتهم قد تم التوصل إلي معايير الاكتمال

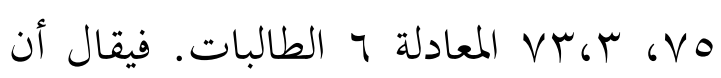
حد الأدنى (KKM) من درس اللغة العربية أكثر الطالبات قد فهمن درس اللغة العربية الذي تم تحديده . V.، إذا كانت قيمتهم قد الذي تم تدريس. أما الطالبات الائي ينلن وصلت إلى معايير الاكتمال حد الأدنى 
القيمة تحت معايير الاكتمال حد الأدنى مثل: طريقة التدريس، وسائل التعليمية، مادة الدرس، التقويم في إيصال المادة الذي يطابق بشكل التعليم فهو تعليم اللغة العربية. وأن هي بالمعادلة الطالبتان و بالقيمة (KKM)

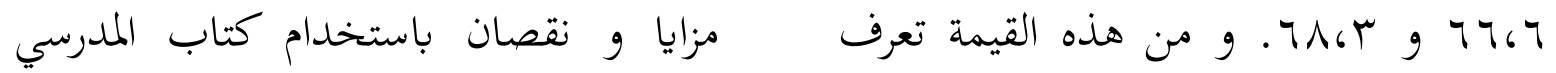
يمكن رؤية من مزايا و نقصان في ذلك كتاب المدرسي. لأن الكتاب الجيد سيجعل التعليم لأن المعلم قد علم بالصحيحة في عملية جيدا و لكن بإتباع التسليم و الشرح الجيد

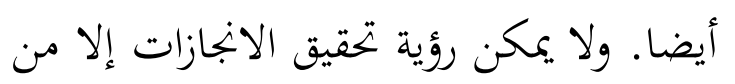

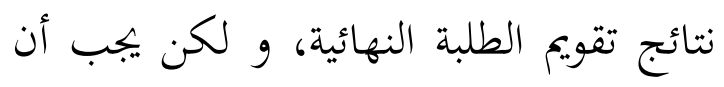
التعليم و قد سعى بان يطبق الطريقة المسرورة لكي الطالبات الممتعة و النشاطة في تعلمهن. ينظر من إستجابة الطلبة حين أثناء التعليم مند بداية حتى فاية، و إجراء التقييم فن كل

$$
\text { فعدد من الطالبات الائي ينلن القيمة تحت } \quad \text { فرصة. }
$$

الطالبتان. فلا يقال أن طريقة التدريس من مراجع الكتابة حسن المعافي، رفعت و بوديمان، أغوس و شرقاوي، علي و الحافظ زيد، عبد. المعلم غير النجاح ولكن لان الطالبات لم

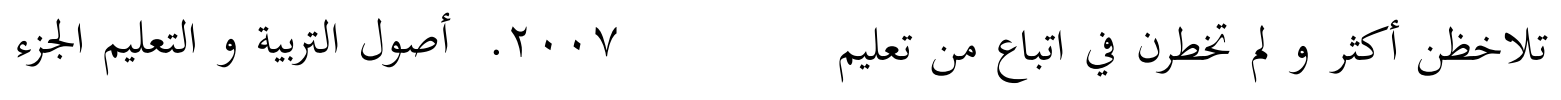
الأول. فونوروكو: بمعهد دار السلام كونتر للتربية الإسلامية الحديثة

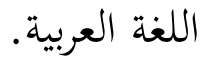

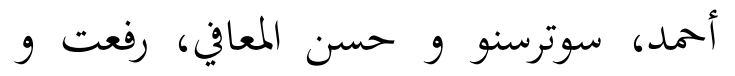
بوديمان، أغوس و الحافظ زيد، عبد. 11 أ. أصول التربية و التعليم الجزء

أن عملية تعليم اللغة العربية الجيدة ينظر من تعليم الذي يهتم ببعض مكونات التعليم 
Arikunto, Suharsimi. 2014. Prosedur Penelitian Suatu Pendekatan Praktik. Jakarta: Rineka Cipta

Arsyad, Azhar. 2010. Bahasa Arab Dan Metode Pengajarannya. Yogyakarta: Pustaka Pelajar

Bahri Djamaroh, Syaeful. 2002. Psikologi Belajar. Jakarta: Rineka Cipta

Creswell, John W. 2014. Research Design Pendekatan Metode Kualitatif, Kuantitatif Dan Campuran. Yoyakarta: Pustaka Pelajar

Hermawan, Acep. 2014. Metodologi Pembelajaran Bahasa Arab. Bandung: Remaja Rosdakarya

Munir. 2011. Perencanaan Sistem Pembelajaran Bahasa Arab Teori Dan Praktek. Yogyakarta: Idea Press

teaching) ed 2, cet 2. Jakarta: Bumi Aksara

Nuha, Ulin. 2012. Metodologi Super Efektif Pembelajaran Bahasa Arab. Yogyakarta: Diva Press

Nuha, Ulin. Ragam Metodologi Dan Media Pembelajaran Bahasa Arab Super Efektif, Kreatif, Dan Inofatif. Yogyakarta: Difa Press

Rahman, Fathur. 2015. Metodologi Pembelajaran Bahasa Arab. Malang: Madani

Rizema Putra, Sitiatava. 2013. Desain Evaluasi Belajar Berbasis Kinerja. Jogjakarta: Diva Press

Sanjaya, Wina. 2006. Strategi Pembelajaran Berorientasi Standar Proses Pendidikan. Jakarta: Kencana

Syah, Muhibbin. 2010. Psikologi Pendidikan Dengan Pendekatan Baru. $\quad$ Bandung: remaja rosdakarya

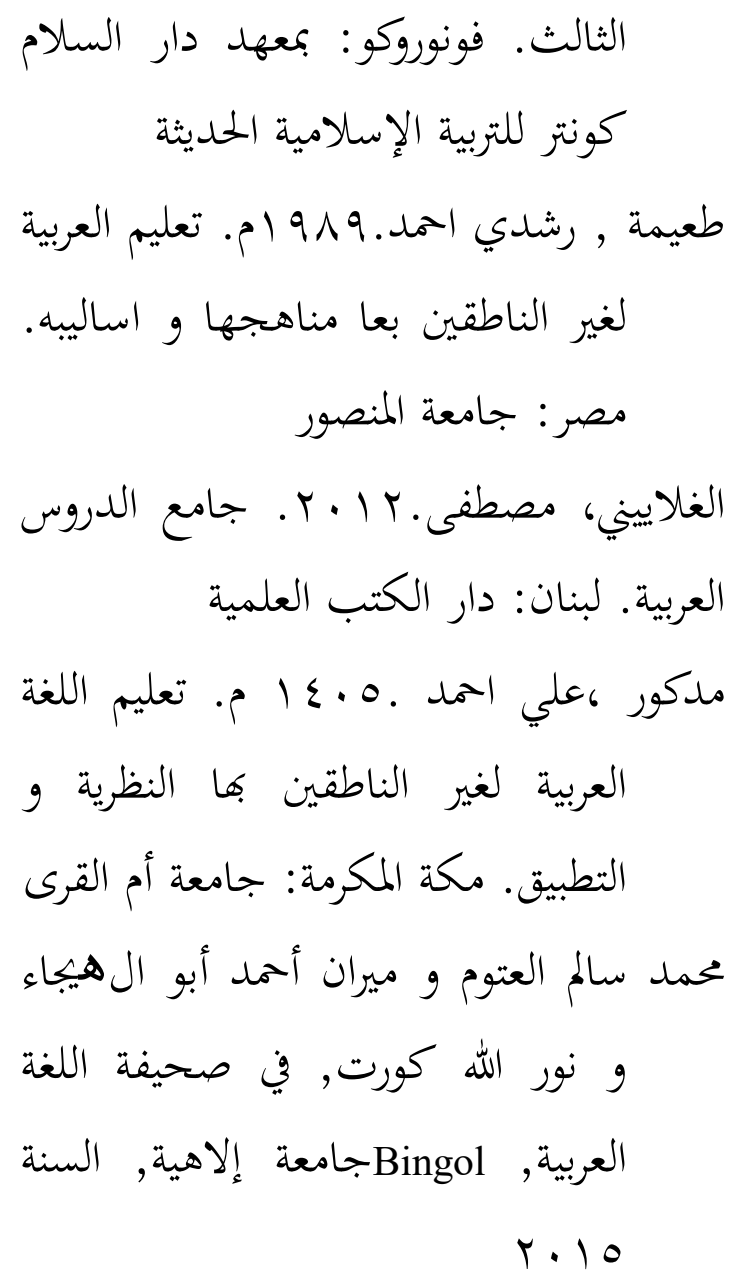

Abdul Wahab, Muhbib. 2008. Epistemologi \& Metodologi Pembelajaran Bahasa Arab. Jakarta: Lembaga Penelitian UIN Syarif Hidayatullah

Ainin, Moh. 2011. Analisa Bahasa Pembelajar Bahasa Arab Sebagai Bahasa Asing, Kajian Analisis Kontrastif, Kesilapan, Dan Koreksi Kesilapan. Malang: Misykat

Asyrofi, Syamsuddin Dan Pransiska, Toni. 2016. Penulisan Buku Teks Bahasa Arab Konsep, Prinsip Problematika Dan Proyeksi. Yogyakarta: Ombak 
Sugiyono. 2015. Metode Penelitian Kuantitatif, Kualitatif Dan $R \& D$. Bandung: Alfabeta

Sitepu. 2015. Penulisan Buku Teks Pelajaran. Bandung: Rosdakarya

Sudjana, Nana. 2008. Dasar-Dasar Proses Belajar Mengajar. Bandung: Sinar Baru Algensindo

Tarigan, Henry Guntur. 2009. Telaah Buku Teks Bahasa Indonesia. Bandung: Angkasa

Zulkifli. 2011. Metode Pengajaran

Bahasa Arab Konvensional Dan Kontemporer. Pekanbaru: Zanara 